\title{
NONLINEAR BEHAVIOUR OF TSUNAMI-LIKE SOLITARY WAVE OVER SUBMERGED IMPERMEABLE STRUCTURES OF FINITE WIDTH
}

\author{
Agnieszka Strusińska-Correia $^{1}$ and Hocine Oumeraci ${ }^{1}$
}

\begin{abstract}
A study on the nonlinear transformation of a tsunami-like solitary wave over impermeable submerged structures of finite widths was performed to examine the feasibility of the integration of such structures into tsunami coastal protection systems. Laboratory experiments with varying structure geometry and incident wave conditions were conducted to determine wave evolution modes, incipient wave breaking and the number of solitons resulting from the wave fission process. The latter was found to be constant for a given relative structure submergence depth and width, irrespective of incident wave conditions, and tended to increase for smaller freeboards and larger barrier widths. The hydraulic performance of the structure, predicted numerically for more realistic tsunami conditions by means of the Boussinesq-type model COULWAVE, was determined in terms of wave transmission, wave reflection and wave energy dissipation coefficients. The rate of wave transmission and energy dissipation was dependent on the breaking conditions over the structure crest: the weakest wave attenuation (approximately 10\%) corresponded to nonbreaking waves, while the highest wave damping (about 25\%) was achieved for the widest relative structure width $\left(\mathrm{B} / \mathrm{L}_{\mathrm{i}}=1.0\right)$ and the smallest relative structure submergence depth $\left(\mathrm{d}_{\mathrm{r}} / \mathrm{h}=0.3\right)$ investigated.
\end{abstract}

Keywords: solitary wave; impermeable submerged structure; soliton fission; wave breaking; wave transmission, reflection and energy dissipation

\section{INTRODUCTION}

The recent tsunami events have significantly contributed to the development of new and more effective strategies for tsunami mitigation. Since tsunami hazard is too hard to predict and to control, multi-defence lines strategies would be preferred instead of the conventional tsunami countermeasures used so far. The aforementioned strategies should be based on a concept of a gradual attenuation of incident tsunami energy by means of both man-made structures and natural barriers, placed from offshore to onshore, as suggested by Oumeraci (2006). The performance of the entire protective system is primarily governed by the effectiveness of its first defence line, which can be exemplarily constructed of broad submerged structures. The incident tsunami energy is expected to be dissipated by prematurely induced wave breaking in the shallower water over the structure crest. The tsunami breaking conditions are controlled in this case by the structure geometry (mainly the width and the height/freeboard), so that a wide barrier would be required to achieve a significant tsunami attenuation.

Submerged structures have been so far employed for storm wave attenuation in order to prevent from coastal erosion (e.g. Aono and Cruz, 1996; Pilarczyk, 2003; Bleck, 2006). Due to the substantially different properties of tsunami and storm waves, this experience cannot be however directly applied to tsunami damping. Interaction of tsunami-like solitary waves with submerged structures of infinite widths has been intensively investigated, with the focus on the inception of wave breaking (e.g. Hara et al., 1992), solitary wave disintegration into solitons (e.g. Madsen and Mei, 1969; Seabra-Santos et al. 1987 and Liu and Cheng, 2001) as well as determination of wave transmission and wave reflection coefficients (e.g. Losada et al., 1989; Goring, 1992). In contrast, solitary wave transformation over submerged barriers of finite widths has attracted much less attention (e.g. Lin, 2004; Grilli et al., 1994 and Lynett, 2007), particularly the phenomenon of wave fission (e.g. Seabra-Santos et al., 1987). Therefore, understanding of the nonlinear processes induced by submerged structures of finite widths was necessary to determine the feasibility of application of these types of structures to tsunami attenuation.

Laboratory experiments were conducted first to provide a deep insight into the process of wave breaking (classification of observed wave breakers and determination of breaking criterion) as well as solitary wave fission (determination of the number of generated solitons). Based on this knowledge, numerical investigations were performed using Boussinesq-type model COULWAVE to predict global processes (i.e. wave transmission, wave reflection and wave energy dissipation, expressed in terms of wave energy) under more realistic tsunami conditions as compared to the laboratory tests.

\footnotetext{
${ }^{1}$ Leichtweiß-Institute for Hydraulic Engineering and Water Resources, Department of Hydromechanics and Coastal Engineering, Technische Universität Braunschweig, Beethovenstr. 51a, Braunschweig, 38106, Germany
} 


\section{LABORATORY EXPERIMENTS ON SOLITARY WAVE INTERACTION WITH IMPERMEABLE SUBMERGED STRUCTURES}

\section{Experimental set-up, programme and measuring devices used}

The nonlinear transformation of a solitary wave over a submerged obstacle was investigated experimentally in the 2 m-wide wave flume of the Leichtweiß-Institute for Hydraulic Engineering and Water Resources (LWI), at the Technische Universität Braunschweig in Germany. The wave flume is about $90 \mathrm{~m}$ long, $1.2 \mathrm{~m}$ high and is equipped with a roubble-type wave absorber, used to minimize wave reflection from the end flume walls (Fig. 1).

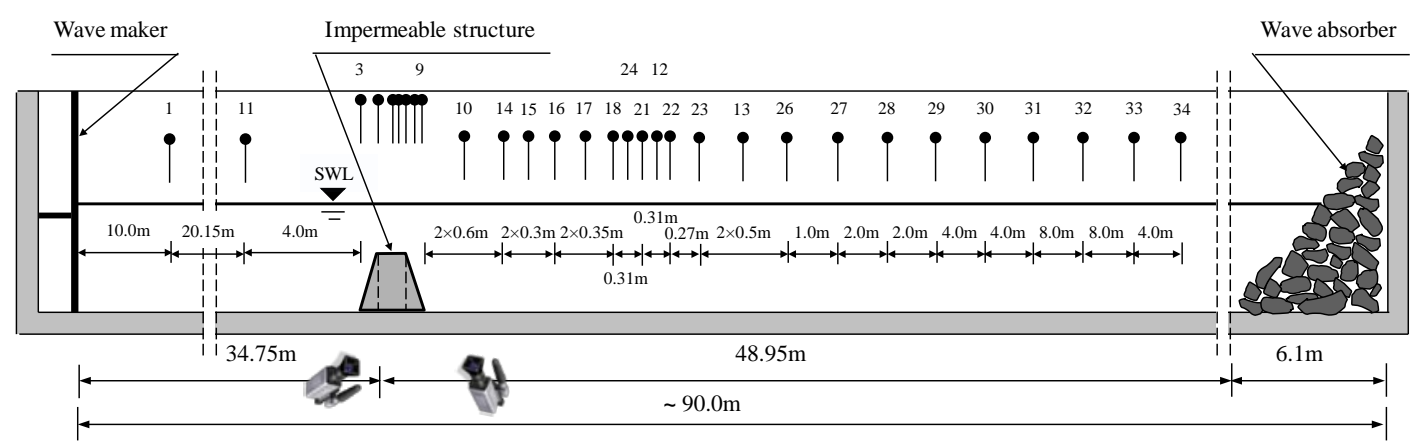

Figure 1. Exemplary experimental set-up of submerged impermeable structure in the $2 \mathrm{~m}$-wide flume of LWI.

The seaward corner of the impermeable obstacle ( $\mathrm{p}=0 \%$ ) was placed at a distance of $34.75 \mathrm{~m}$ from a wave maker as shown in Fig. 1. The structure was designed of two identical steel frame units, each $1.0 \mathrm{~m}$ long and $2.0 \mathrm{~m}$ wide, covered with plywood plates at the top, front and back. Two widths of the barrier crest were tested: $\mathrm{B}=1.0$ and $2.0 \mathrm{~m}$ by using the single or the double model unit, respectively. Depending on the total water depth in front of the structure $(\mathrm{h}=0.5,0.6,0.7 \mathrm{~m})$ and the structure height $\left(h_{\mathrm{r}}=0.3,0.4,0.5 \mathrm{~m}\right)$, the submergence depth of the barrier, given as:

$$
d_{r}=h-h_{r}
$$

varied from $d_{r}=0.1 m$ to $d_{r}=0.4 m$ (see Fig. 2). The barrier was equipped with removable seaside and landward slopes (1:2) in order to investigate the effect of the barrier shape (rectangular and trapezoidal) on wave behaviour. Additional tests without the submerged structure (i.e. $\mathrm{B}=0.0 \mathrm{~m}$ and $\mathrm{h}_{\mathrm{r}}=0.0 \mathrm{~m}$ ) were performed for water depth of $\mathrm{h}=0.6 \mathrm{~m}$ to compare wave behaviour with and without the barrier.

Solitary waves of nominal wave height $\mathrm{H}_{\mathrm{i}, \mathrm{nom}}=0.06-0.22 \mathrm{~m}$ (with an interval of $0.02 \mathrm{~m}$ ) were generated in a deep portion of water $h$ by means of a piston-type wave maker. The corresponding nominal incident wavelength, varying from $L_{i, \text { nom }}=3.2 \mathrm{~m}$ to $\mathrm{L}_{\mathrm{i}, \text { nom }}=8.04 \mathrm{~m}$, was calculated by means of the formula proposed by Dean and Dalrymple (1991):

$$
L_{i, \text { nom }}=2 \frac{2.12 h}{\sqrt{H_{i, \text { nom }} / h}}
$$

The experimental programme is summarized in Table 1. Dimensionless parameters, describing incident solitary wave conditions and reef geometry, were applied to the analysis of the experimental results. The most relevant parameters are: relative structure height $\left(\mathrm{h}_{\mathrm{r}} / \mathrm{h}=0.0-0.83\right.$ ), relative submergence depth $\left(\mathrm{d}_{\mathrm{r}} / \mathrm{h}=0.17-1.0\right)$ and relative structure crest width $\left(\mathrm{B} / \mathrm{L}_{\mathrm{i} \text {,gen }}=0.12-0.63\right)$. In the latter, generated wavelength $L_{i, g e n}$ was obtained from Eq. (2) by replacing incident nominal wave height $H_{i, \text { nom }}$ by incident generated wave height $H_{i, g e n}$ (see Table 2 ).

Water free surface elevation was measured in front of, over and behind the submerged structure by means of wire-resistance wave gauges (WG) as shown in Fig. 1. The number and the distance among the measuring devices varied in the tests to ensure the best capture of the inception of wave breaking and wave disintegration into solitons. These two processes were recorded by two video cameras installed at the flume walls. 
a) Rectangular-shaped structure
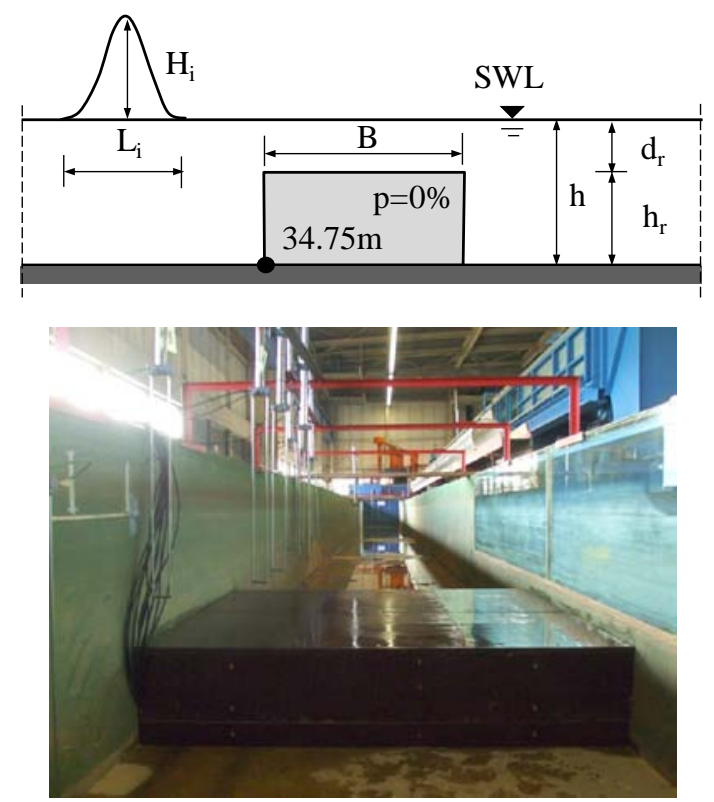

b) Trapezoidal-shaped structure
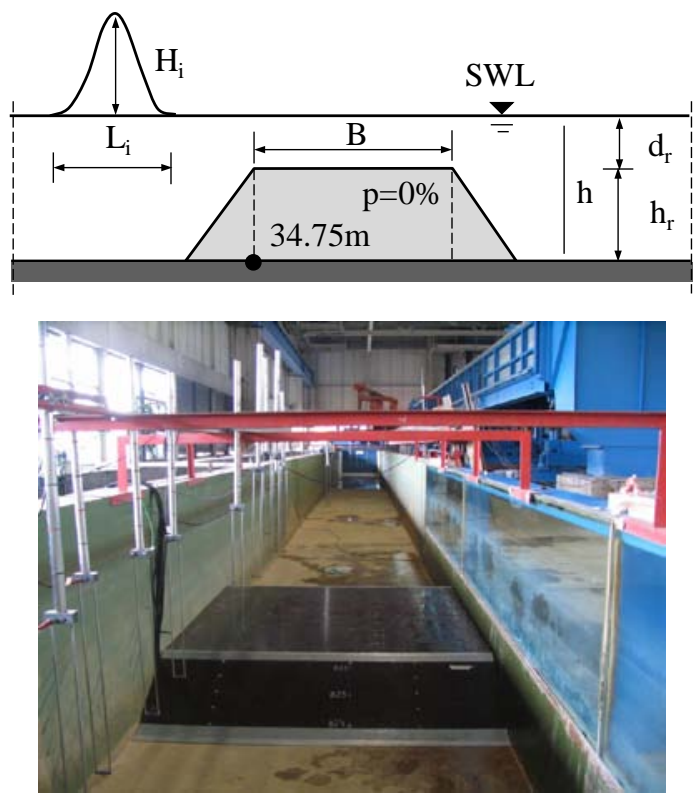

Figure 2. Geometry of tested impermeable submerged structures: a) of rectangular shape, b) of trapezoidal shape.

\begin{tabular}{|c|c|c|c|c|c|c|}
\hline & $\mathrm{h}_{\mathrm{r}}[\mathrm{m}]$ & $\mathrm{d}_{\mathrm{r}}[\mathrm{m}]$ & $\mathrm{B}[\mathrm{m}]$ & Slopes [-] & $\mathrm{H}_{\mathrm{i}, \text { nom }}[\mathrm{m}]$ & $\mathrm{L}_{\mathrm{i}, \mathrm{nom}}[\mathrm{m}]$ \\
\hline $\mathrm{h}=0.5 \mathrm{~m}$ & $0.3,0.4$ & $0.2,0.1$ & $1.0,2.0$ & $1: 2$ & $0.06-0.22$ & $6.12-3.20$ \\
\hline $\mathrm{h}=0.6 \mathrm{~m}$ & $0.0,0.3,0.4,0.5$ & $0.6,0.3,0.2,0.1$ & $0.0,1.0,2.0$ & 1:2, no slopes & $0.06-0.22$ & $8.04-4.20$ \\
\hline $\mathrm{h}=0.7 \mathrm{~m}$ & $0.3,0.4,0.5$ & $0.4,0.3,0.2$ & $1.0,2.0$ & $1: 2$ & $0.10-0.22$ & $7.85-5.29$ \\
\hline
\end{tabular}

\begin{tabular}{|c|c|c|c|c|c|c|c|c|c|c|}
\hline \multirow[t]{3}{*}{$\mathrm{h}=0.5 \mathrm{~m}$} & $\mathrm{H}_{\mathrm{i}, \text { nom }}[\mathrm{m}]$ & $\begin{array}{l}0.06 \\
6.12\end{array}$ & $\begin{array}{l}0.08 \\
5.30\end{array}$ & $\begin{array}{l}0.10 \\
4.74\end{array}$ & $\begin{array}{l}0.12 \\
4.33\end{array}$ & $\begin{array}{l}0.14 \\
4.01\end{array}$ & $\begin{array}{l}0.16 \\
3.75\end{array}$ & $\begin{array}{l}0.18 \\
3.53\end{array}$ & $\begin{array}{l}0.20 \\
3.35\end{array}$ & $\begin{array}{l}0.22 \\
3.20\end{array}$ \\
\hline & $\mathrm{H}_{\mathrm{i}, \text { gen }}[\mathrm{m}]$ & 0.06 & 0.08 & 0.11 & 0.13 & 0.15 & 0.18 & 0.19 & 0.22 & 0.24 \\
\hline & $\mathrm{L}_{\mathrm{i}, \text { gen }}[\mathrm{m}]$ & 6.12 & 5.14 & 4.60 & 4.21 & 3.85 & 3.57 & 3.43 & 3.20 & 3.08 \\
\hline \multirow[t]{4}{*}{$\mathrm{h}=0.6 \mathrm{~m}$} & $\mathrm{H}_{\mathrm{i}, \text { nom }}[\mathrm{m}]$ & 0.06 & 0.08 & 0.10 & 0.12 & 0.14 & 0.16 & 0.18 & 0.20 & 0.22 \\
\hline & $\mathrm{L}_{\mathrm{i}, \mathrm{nom}}[\mathrm{m}]$ & 8.04 & 6.97 & 6.23 & 5.69 & 5.27 & 4.93 & 4.64 & 4.41 & 4.20 \\
\hline & $\mathrm{H}_{\mathrm{i}, \text { gen }}[\mathrm{m}]$ & 0.06 & 0.08 & 0.11 & 0.13 & 0.15 & 0.18 & 0.19 & 0.22 & 0.24 \\
\hline & $L_{i, g e n}[\mathrm{~m}]$ & 8.04 & 6.76 & 6.05 & 5.53 & 5.05 & 4.70 & 4.51 & 4.21 & 4.05 \\
\hline \multirow[t]{4}{*}{$\mathrm{h}=0.7 \mathrm{~m}$} & $\mathrm{H}_{\mathrm{i}, \mathrm{nom}}[\mathrm{m}]$ & - & - & 0.10 & 0.12 & 0.14 & 0.16 & 0.18 & 0.20 & 0.22 \\
\hline & $\mathrm{L}_{\mathrm{i}, \text { nom }}[\mathrm{m}]$ & & & 7.58 & 7.17 & 6.64 & 6.21 & 5.85 & 5.55 & 5.29 \\
\hline & $\mathrm{H}_{\mathrm{i}, \text { gen }}[\mathrm{m}]$ & - & - & 0.11 & 0.13 & 0.15 & 0.18 & 0.19 & 0.22 & 0.24 \\
\hline & $L_{i, g e n}[\mathrm{~m}]$ & & & 7.63 & 6.97 & 6.37 & 5.92 & 5.68 & 5.31 & 5.10 \\
\hline
\end{tabular}

\section{Effect of structure shape on solitary wave behaviour}

The influence of structure shape on the incipient wave breaking and wave breaker types was investigated in the experiments with water depth of $\mathrm{h}=0.6 \mathrm{~m}$. As indicated in Fig. 3, identical nonbreaking wave conditions were achieved for the trapezoidal and the rectangular barriers. In the tests with breaking waves, a difference between the breaker types occurred in two cases, namely (i) spilling breaker $\left(\mathrm{H}_{\mathrm{i}, \text { nom }} / \mathrm{d}_{\mathrm{r}}=0.22, \mathrm{~B} / \mathrm{L}_{\mathrm{i}}=1.8\right)$ observed for the rectangular barrier became transitional breaker for the trapezoidal structure, (ii) transition breaker $\left(\mathrm{H}_{\mathrm{i}, \text { nom }} / \mathrm{d}_{\mathrm{r}}=0.35, \mathrm{~B} / \mathrm{L}_{\mathrm{i}}=1.2\right)$ observed for the rectangular barrier became plunging breaker for the trapezoidal barrier. Taking into account the negligible effect of the structure shape on the solitary wave breaking conditions, trapezoidal-shaped barrier was used solely in further experiments with water depth of $\mathrm{h}=0.5$ and $0.7 \mathrm{~m}$. 
a) Rectangular structure

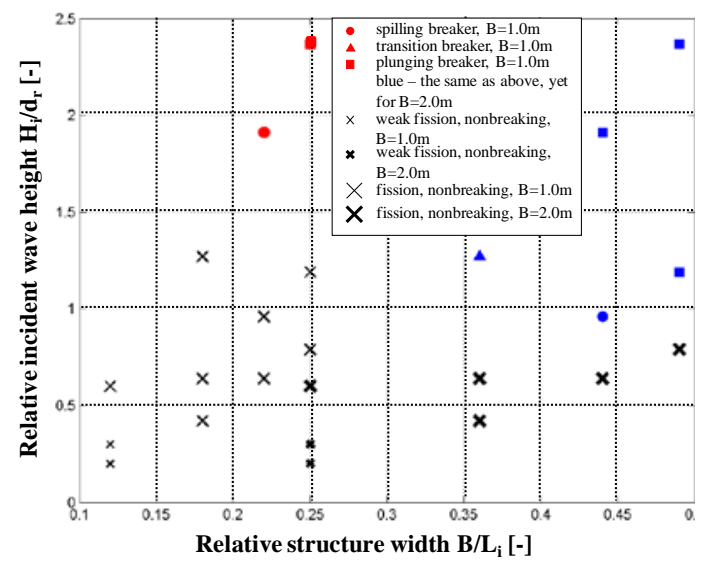

b) Trapezoidal structure (slopes 1:2)

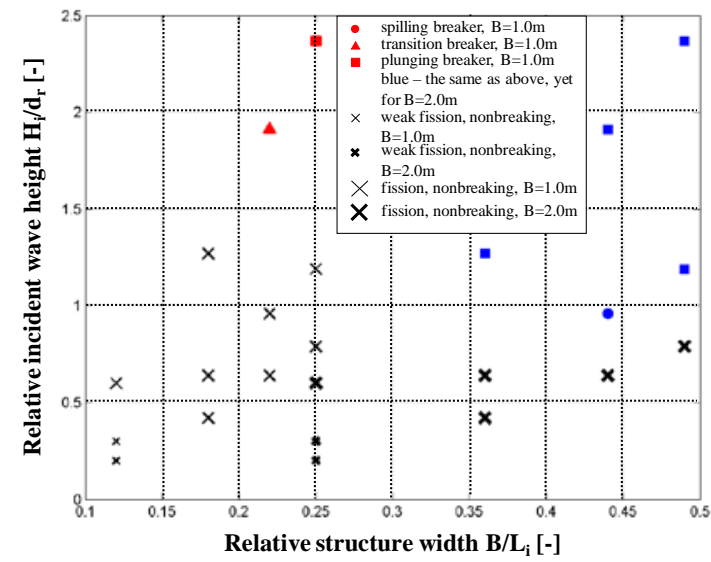

Figure 3. Influence of barrier shape on solitary wave breaking conditions (investigated for water depth of $\mathrm{h}=0.6 \mathrm{~m}$ ): a) for rectangular structure, b) for trapezoidal structure.

\section{Classification of solitary wave evolution modes}

Several patterns of solitary wave propagation were recognized and classified as follows under the consideration of the inception of wave breaking and wave fission:

1. Nonbreaking waves:

- Wave evolution mode 1 (WEM1): solitary wave propagating without generation of wave fission and wave breaking, observed in the experiments without the submerged structure $(\mathrm{B}=0.0 \mathrm{~m}$ and $\mathrm{h}_{\mathrm{r}}=0.0 \mathrm{~m}$ ), as illustrated in Fig. 4.

- Wave evolution mode 2 (WEM2): weak fission of a single transmitted nonbreaking wave for which an incomplete and relatively late development of a second soliton was observed as compared to the other evolution modes. This was due to the fact that the propagation distance between the fission inception point and the end of the flume was not long enough to allow for the soliton separation from the leading wave. No wave breaking was induced over the submerged barrier. This evolution mode was typical for weakly nonlinear waves $\left(\mathrm{H}_{\mathrm{i}, \mathrm{nom}} / \mathrm{h}=0.1\right)$, propagating over a structure of crest width of $\mathrm{B}=1.0$ and $2.0 \mathrm{~m}$, and of relatively large freeboard $\left(\mathrm{d}_{\mathrm{r}} / \mathrm{h}=0.33\right.$ and 0.5$)$.

- Wave evolution mode 3 (WEM3): fission of a single transmitted nonbreaking wave with a development of at least of two solitons of clearly defined troughs as shown in Fig. 5. This was the most often pattern observed in the tests with the nonbreaking waves.

2. Breaking waves:

- Wave evolution mode 4 (WEM4): fission of a single transmitted wave followed by breaking of the leading wave, occurring when the incipient wave breaking was induced over the leaward structure slope. The second soliton appeared as a small hump at the rear part of the first soliton when the solitary wave entered the shallower water over the barrier crest. Further development of the fission was however limited by wave breaking process; however it advanced once the breaking event was completed.

- Wave evolution mode 5 (WEM5): breaking of a single transmitted wave followed by fission of the broken leading wave, observed in the tests with increased relative incident wave height $H_{i} / h$, decreased relative submergence depth $d_{r} / h$ and larger relative structure width $B / L_{i}$. As compared to the wave evolution mode WEM4, the inception point of wave breaking was located closer to the seaward structure toe, and thus the incident solitary wave broke first and further disintegrated into solitons (Fig. 6).

The experimental results clearly indicated that the inception of wave breaking did not suppress the generation of wave fission, irrespectively of the order of the generation of these two processes (see wave evolution modes WEM4 and WEM5). This wave behaviour was also reported by Liu and Cheng (2001) for solitary waves propagating over submerged, impermeable, infinitely long steps. In contrast, Losada et al. (1989), who performed laboratory tests on solitary wave transformation over submerged impermeable structures of both infinite and finite widths, postulated that wave fission can be generated only if wave breaking is induced first. 


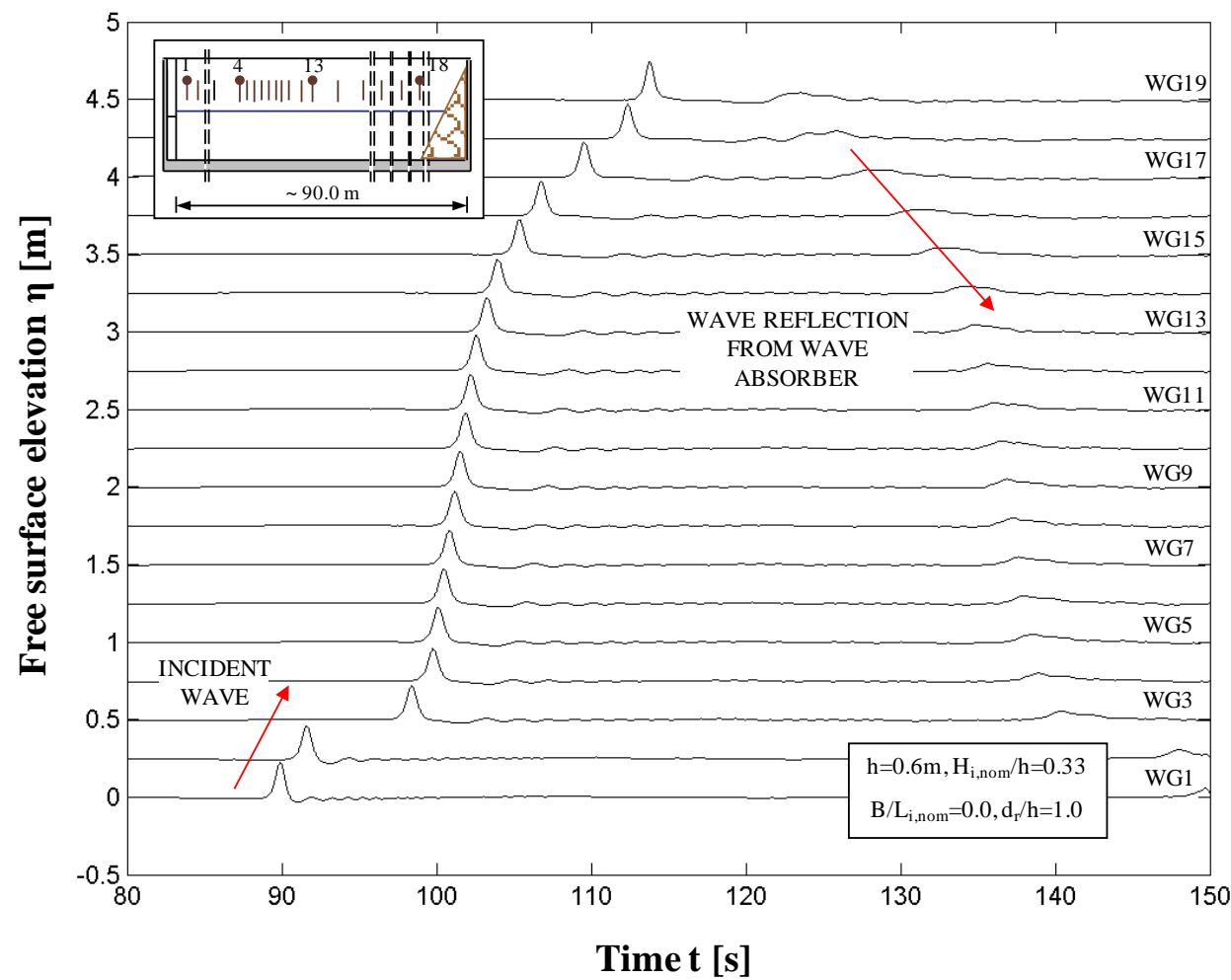

Figure 4. Exemplary solitary wave propagation in a test without submerged structure (wave evolution mode WEM1).
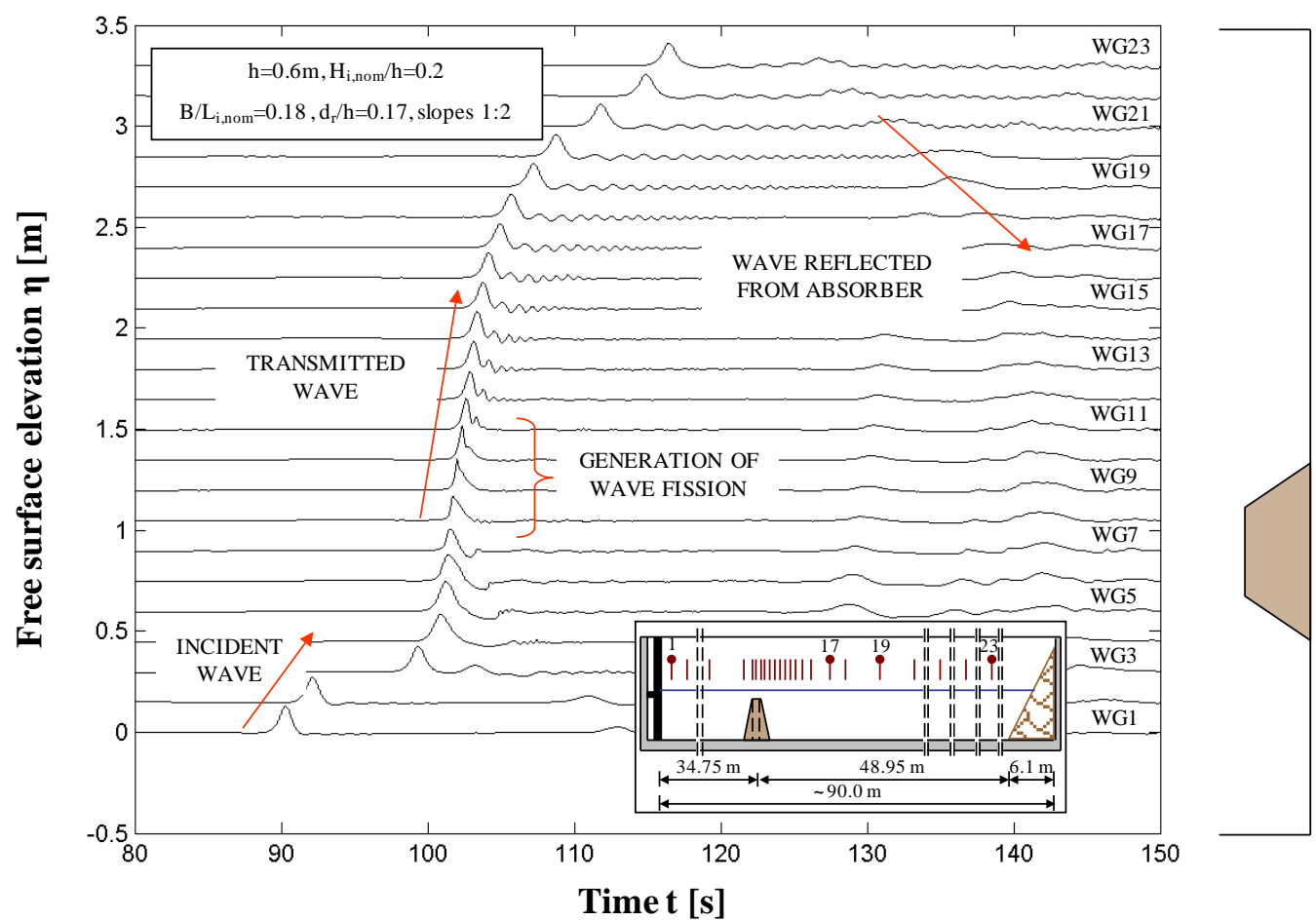

Figure 5. Exemplary disintegration of nonbreaking solitary wave into solitons (wave evolution mode WEM3). 


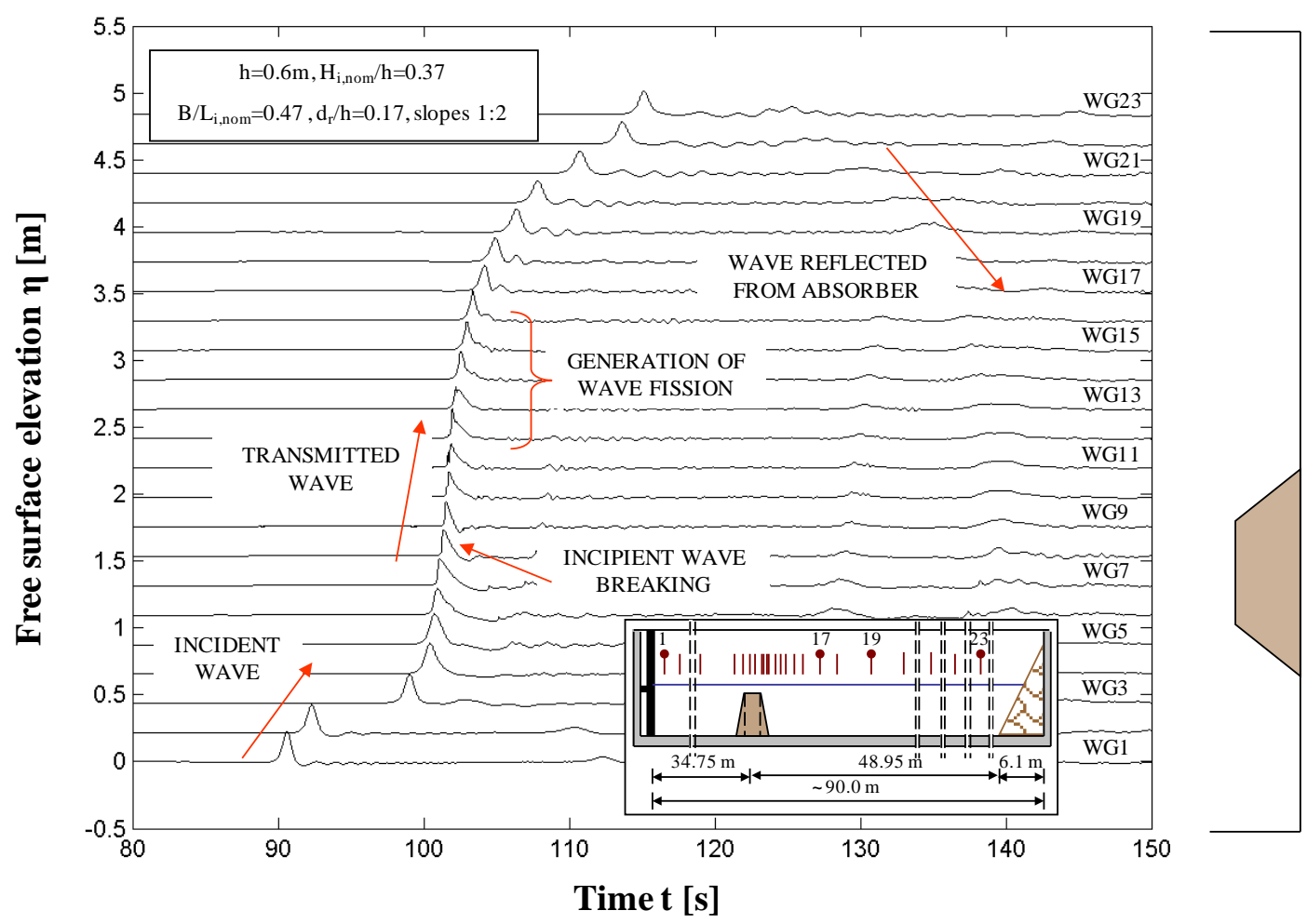

Figure 6. Exemplary breaking of solitary wave followed by development of solitons (wave evolution mode WEM5).

\section{Determination of solitary wave breaking criterion}

A criterion for the incipient breaking of a solitary wave over a submerged impermeable structure was determined on the basis of the tests with the trapezoidal barrier, water depth $h=0.5,0.6,0.7 \mathrm{~m}$, nominal incident wave height $\mathrm{H}_{\mathrm{i} \text {,nom }}=0.06-0.22 \mathrm{~m}$ and structure width $\mathrm{B}=1.0$ and $2.0 \mathrm{~m}$. The criterion, expressed in terms of relative structure width $B / L_{i}$ and relative wave height $H_{i} / d_{r}$, is given by the following equation and is plotted in Fig. 7:

$$
H_{i} / d_{r}=0.573\left(B / L_{i}\right)^{-0.6}
$$

where $H_{i}$ and $L_{i}$ represent the incident generated wave conditions.

Three wave breakers types were identified, namely spilling breaker, plunging breaker and transition breaker (which is a transition between the spilling and the plunging breakers). The corresponding wave conditions and the structure geometry are shown in Fig. 7.

\section{Determination of solitons number}

The phenomenon of wave fission was caused by the water depth change as the incident solitary wave, propagating from the region of water depth $h$ in front of the submerged structure, entered the region of shallower water $d_{r}$ over the barrier crest. Successive humps were generated at the rear part of the wave (termed solitons), so that the wave could remain stable as the wave nonlinearity increased. At least two solitons were observed in each test (where the leading wave represented the first soliton), as exemplarily presented in Fig. 8. The generation of the second soliton was accompanied by the increase of the height of the leading wave, which was particularly distinct for nonbreaking waves.

The number of the emerged solitons was determined from the measurements of water free surface elevation by wave gauges, which arrangement was adjusted to each tested conditions. This allowed for a very detailed capture of the generation and the development of the solitons. Since identification of the generated solitons from profiles of breaking waves was very difficult, solitons number $N$ was defined solely for nonbreaking waves, generated at water depth of $\mathrm{h}=0.6 \mathrm{~m}$ and interacting with the trapezoidal-shaped structures. As shown in Fig. 9, the number of the generated solitons was not only dependent on relative submergence depth $d_{r} / h$, as reported in previous investigations (e.g. Johnson, 1972 and Seabra-Santos et al., 1987), but also by relative structure width $B / L_{i}$. The effect of the latter 
parameter on the enhancement of wave fission could not be determined in those studies, since infinitely long submerged steps were considered.

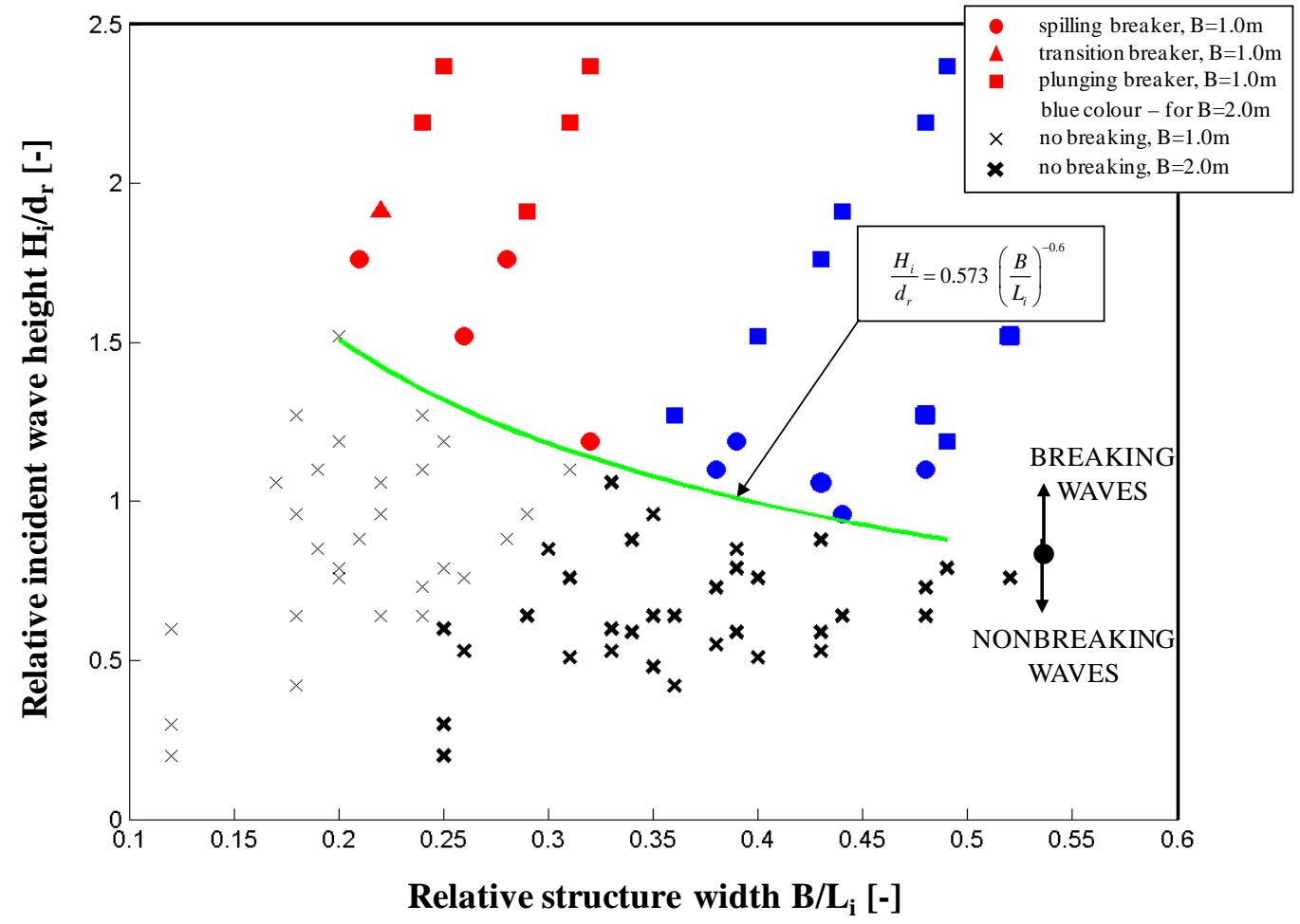

Figure 7. Criterion for solitary wave breaking over submerged impermeable structures of finite widths.

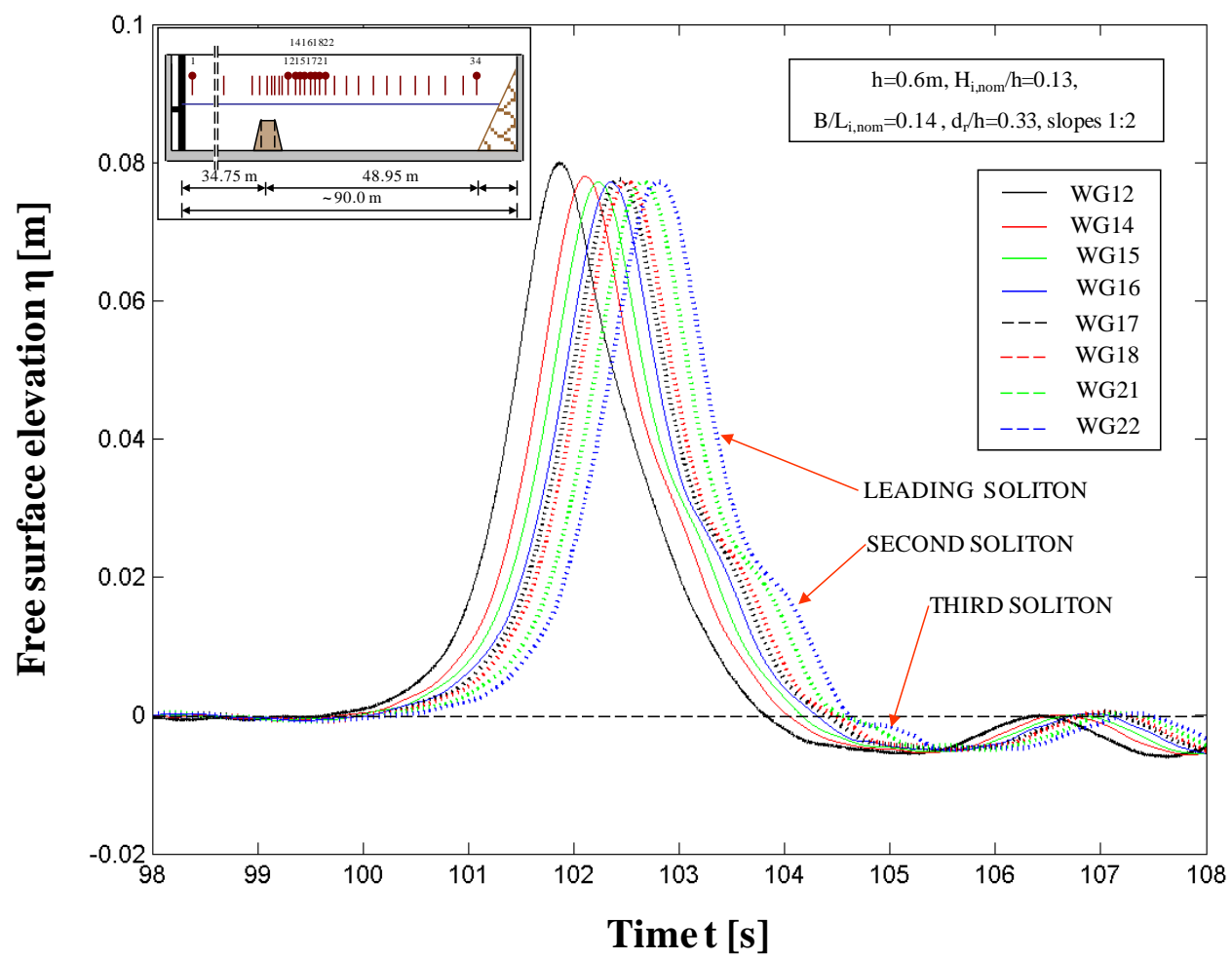

Figure 8. Exemplary generation and evolution of solitons for nonbreaking wave. 


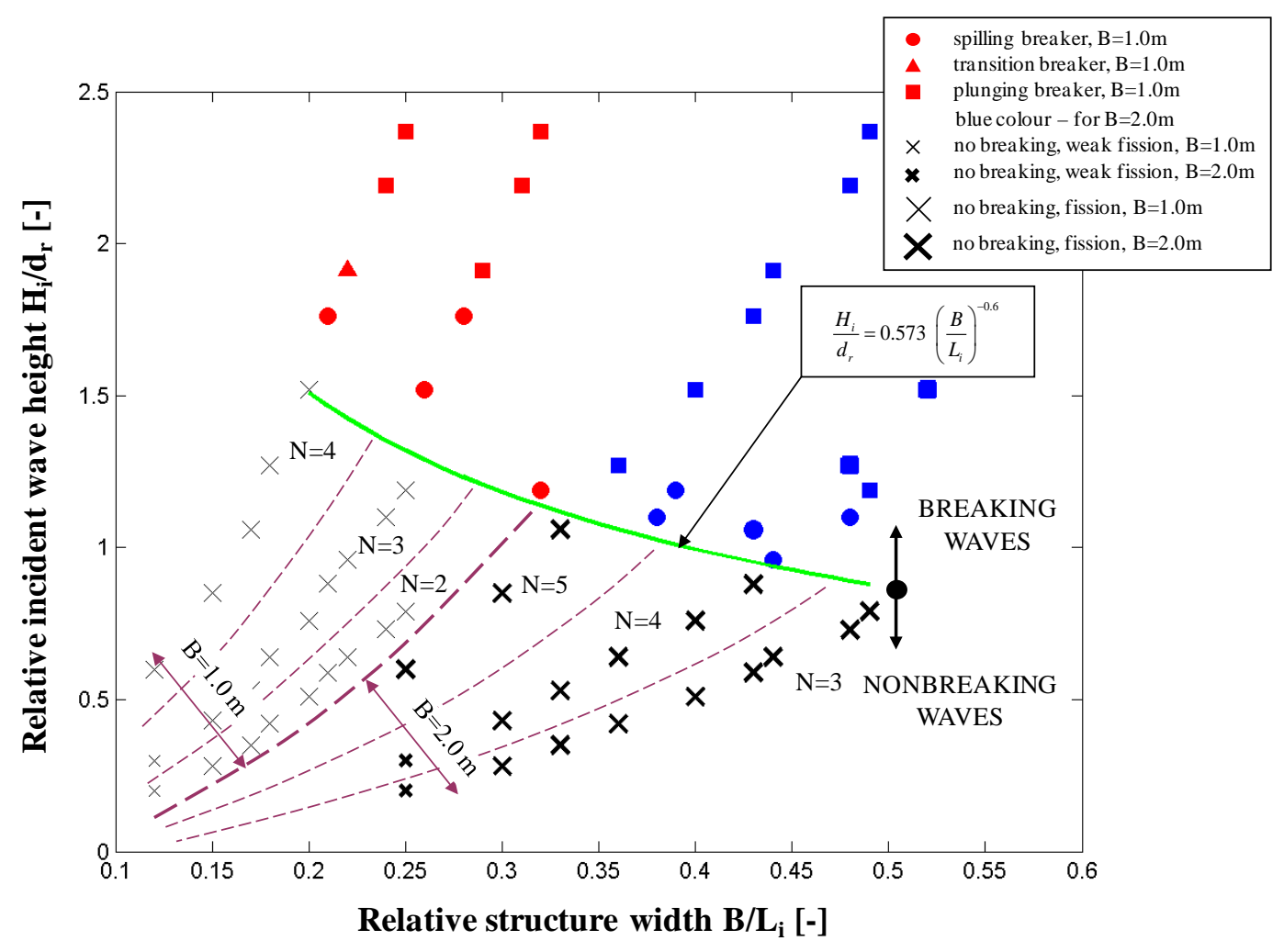

Figure 9. Number of solitons determined for nonbreaking solitary waves propagating over submerged impermeable structures of finite widths.

The solitons number increased with decreasing relative submergence depth and was independent of the incident solitary wave conditions. In case of structure width of $\mathrm{B}=1.0 \mathrm{~m}$, it yielded $\mathrm{N}=2$ for $\mathrm{d}_{\mathrm{r}} / \mathrm{h}=0.5, \mathrm{~N}=3$ for $\mathrm{d}_{\mathrm{r}} / \mathrm{h}=0.33$ and $\mathrm{N}=4$ for $\mathrm{d}_{\mathrm{r}} / \mathrm{h}=0.17$. The longer propagation distance in the shallower water over the structure crest, associated with the wider structures of $\mathrm{B}=2.0 \mathrm{~m}$, was more favourable for the development of the fission process. In this case the solitons number was $\mathrm{N}=3$ for $\mathrm{d}_{\mathrm{r}} / \mathrm{h}=0.5, \mathrm{~N}=4$ for $\mathrm{d}_{\mathrm{r}} / \mathrm{h}=0.33$ and $\mathrm{N}=5$ for $\mathrm{d}_{\mathrm{r}} / \mathrm{h}=0.17$.

The number of the solitons generated over the structures of finite widths was compared in Table 3 with those obtained for infinitely long barriers - theoretically by Johnson (1972):

$$
d_{r} / h=[0.5 N(N+1)]^{-4 / 9}
$$

Germain (1984) and Kabbaj (1985):

$$
M=0.5\left\{\left[1+\frac{16\left(h / d_{r}\right)^{5 / 2}}{1+\left(h / d_{r}\right)^{1 / 2}}\right]^{1 / 2}-1\right\}, \quad N=|M|, \quad \text { N is largest integer } \leq \mathrm{M}(5)
$$

as well as experimentally/numerically by Madsen and Mei (1969), Johnson (1972) and Seabra-Santos et al. (1987). The solitons number tended to be similar for the structures of both finite and infinite widths: ca. $\mathrm{N}=2$ - 3 for relative submergence depths of $\mathrm{d}_{\mathrm{r}} / \mathrm{h}=0.5$, while $\mathrm{N}=3-5$ for $\mathrm{d}_{\mathrm{r}} / \mathrm{h}=0.33$. However, significant difference of the solitons number occurred for the smallest relative submergence depth investigated $\left(\mathrm{d}_{\mathrm{r}} / \mathrm{h}=0.17\right)$, namely $4-5$ solitons were generated for the barrier of a finite width and twice as much for the submerged steps $(\mathrm{N}=9-10)$. Additionally, there were some minor differences in the solitons number predicted by the theoretical formulae by Johnson (1972) (see Eq. 4) and Germain (1984) and Kabbaj (1985) (see Eq. 5). For the latter, the solitons number tended to be reduced by one. 


\begin{tabular}{|c|c|c|c|c|c|c|c|}
\hline \multirow[t]{2}{*}{$\mathrm{d}_{\mathrm{r}} / \mathrm{h} \mathrm{[-]}$} & \multicolumn{2}{|c|}{$\begin{array}{l}\text { Obstacles of finite } \\
\text { widths (own tests) }\end{array}$} & \multicolumn{5}{|c|}{$\begin{array}{l}\text { Obstacles of infinite widths (theoretical, experimental/numerical } \\
\text { studies) }\end{array}$} \\
\hline & $\mathrm{B}=1.0 \mathrm{~m}$ & $\mathrm{~B}=2.0 \mathrm{~m}$ & $\begin{array}{l}\text { Johnson } \\
\text { (1972), } \\
\text { Eq. } 4\end{array}$ & $\begin{array}{l}\text { Germain } \\
(1984) \text { and } \\
\text { Kabbaj } \\
(1985) \text {, Eq. } 5\end{array}$ & $\begin{array}{l}\text { Madsen } \\
\text { and Mei } \\
(1969)\end{array}$ & $\begin{array}{l}\text { Johnson } \\
\text { (1972) }\end{array}$ & $\begin{array}{l}\text { Seabra- } \\
\text { Santos et al. } \\
(1987)\end{array}$ \\
\hline 0.67 & - & - & 2 & 1 & - & - & 2 (NB) \\
\hline 0.61 & - & - & 2 & 2 & - & 2 (NB) & - \\
\hline 0.60 & - & - & 2 & 2 & - & - & 2 (NB) \\
\hline 0.55 & - & - & 3 & 2 & - & 3 (NB) & 2 (NB) \\
\hline 0.50 & $2(\mathrm{NB})^{2}$ & $3(\mathrm{NB})$ & 3 & 2 & $3(\mathrm{NB})$ & 3 (NB) & 3 (NB) \\
\hline 0.45 & - & - & 3 & 3 & - & - & - \\
\hline 0.45 & - & - & 3 & 3 & - & - & 3 (NB) \\
\hline 0.33 & $3(\mathrm{NB})$ & $4(\mathrm{NB})$ & 5 & 4 & - & - & $4(\mathrm{Br})^{3}$ \\
\hline 0.17 & $4(\mathrm{NB})$ & $5(\mathrm{NB})$ & 10 & 9 & - & - & - \\
\hline
\end{tabular}

\section{NUMERICAL PREDICTION OF DAMPING PERFORMANCE OF SUBMERGED IMPERMEABLE STRUCTURE}

\section{Numerical set-up and numerical model}

Due to the limitations of tsunami generation under laboratory conditions, the damping performance of an impermeable submerged structure under tsunami impact was determined numerically. The tsunami-like solitary wave of different initial conditions (see Table 4) propagated from a region of deeper water towards a shelf of a slope of 1:50, on top of which the barrier of varying geometry was placed in water depth of $\mathrm{h}=1.0 \mathrm{~m}$ (Fig. 10). The barrier was of trapezoidal shape (with slopes 1:10), with relative crest width $\mathrm{B} / \mathrm{L}_{\mathrm{i}}=0.0-1.0$ (with an increment of 0.1 ) and relative structure height $\mathrm{h}_{\mathrm{r}} / \mathrm{h}=0.0,0.5,0.6,0.7$. Horizontal length of the shelf $x_{1}$ resulted from offshore water depth $h_{o}$, while distance $x_{2}$ in front of the structure equaled one incident wavelength and was necessary to determine the local incident wave conditions listed in Table 4. Distance $x_{3}$ represents the total structure width and varied with the relative crest width, while the length of distance $x_{4}$ was chosen to allow for the determination of wave transmission and development of wave fission.

\begin{tabular}{|l|l|l|l|l|}
\hline \multicolumn{5}{|c|}{ Table 4. Solitary wave parameters examined in numerical simulations. } \\
\hline \multicolumn{4}{|l|l|l|l|}{ Initial wave conditions in farfield } & \multicolumn{4}{l|}{ Local incident wave conditions } \\
\hline $\mathrm{H}_{\mathrm{o}} / \mathrm{h}_{\circ}[-]$ & $\mathrm{h}_{\mathrm{o}} / \mathrm{h}[-]$ & $\mathrm{H}_{\mathrm{i}} / \mathrm{h}[-]$ & $\mathrm{L}_{\mathrm{i}} / \mathrm{h}[-]$ & $\mathrm{h}[\mathrm{m}]$ \\
\hline 0.021 & 3.5 & 0.10 & 100 & 1.0 \\
0.026 & 4.0 & 0.15 & 100 & 1.0 \\
0.029 & 4.5 & 0.20 & 100 & 1.0 \\
0.030 & 5.0 & 0.25 & 100 & 1.0 \\
\hline
\end{tabular}

Wave propagation was predicted numerically by means of fully nonlinear, extended Boussinesqtype equations (Liu, 1994) implemented in the model COULWAVE developed by Lynett (2002), where horizontal velocity field in computed at water level $\mathrm{z}_{\alpha}=-0.531 \mathrm{~h}$ (Nwogu, 1993). More details on the numerical scheme can be found in Lynett (2002) and in the Ph.D. thesis of Strusińska (2010).

Frictional losses are neglected in the simulations in order to determine explicitly the rate of wave attenuation by the submerged structure. The spatial grid resolution was expressed in terms of the local water depth and varied with the incident wave conditions investigated: $\Delta \mathrm{x} / \mathrm{h}=0.1$ for $\mathrm{H}_{\mathrm{i}} / \mathrm{h}=0.1,0.15$ and $\Delta \mathrm{x} / \mathrm{h}=0.15$ for $\mathrm{H}_{\mathrm{i}} / \mathrm{h}=0.2,0.25$. The time step was constant and yielded $\Delta \mathrm{t}=0.05 \mathrm{~s}$.

\footnotetext{
${ }^{2} \mathrm{NB}$ - nonbreaking waves

${ }^{3} \mathrm{Br}$ - breaking waves
} 


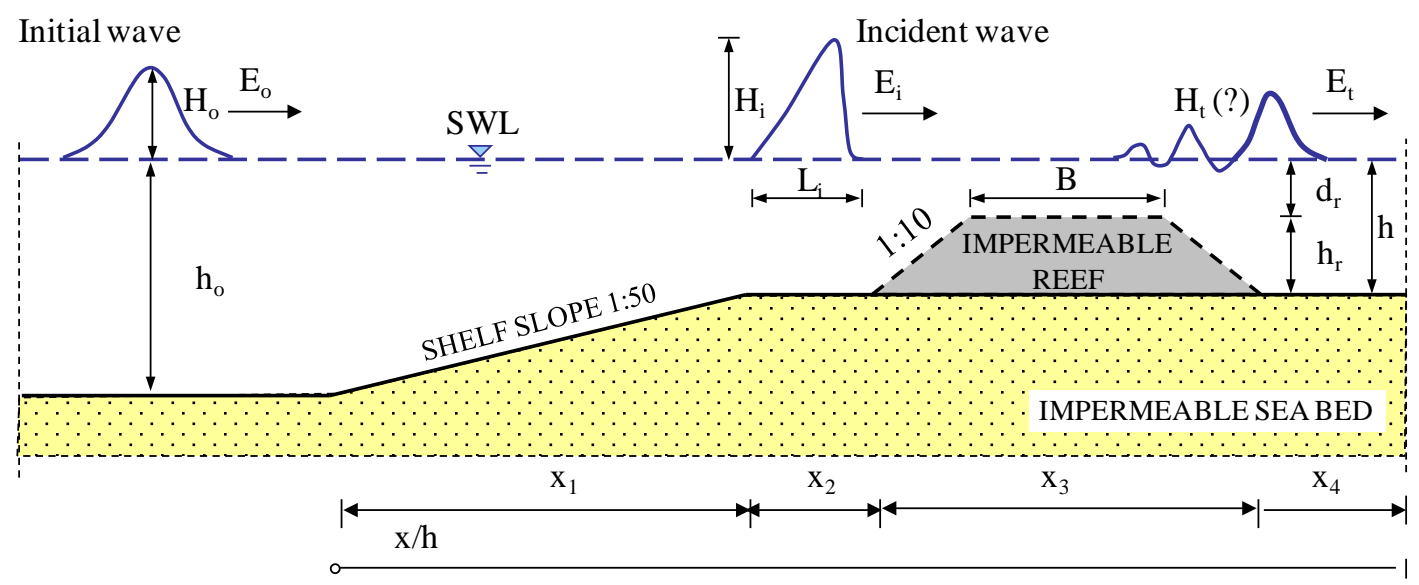

Figure 10. Numerical set-up of the impermeable reef structure on a shelf.

Calculation of wave transmission, wave reflection and wave energy dissipation coefficients

The damping performance of the submerged structure was determined in terms of wave transmission coefficient $K_{t}$, wave reflection coefficient $K_{r}$ and wave energy dissipation coefficient $K_{d}$, expressed as a function of wave energy:

$$
K_{t}=\sqrt{E_{t} / E_{i}}, \quad K_{r}=\sqrt{E_{r} / E_{i}}, \quad K_{d}=\sqrt{1-K_{t}^{2}-K_{r}^{2}}
$$

Energy of incident wave $E_{i}$, transmitted wave $E_{t}$ and reflected wave $E_{r}$ was calculated as a total wave energy $E_{\text {tot }}$, consisting of potential $E_{p}$ and kinetic $E_{k}$ energy:

$$
E_{\text {tot }}=E_{p}+E_{k}
$$

The potential and the kinetic energy were determined according to Eqs. 8 and 9, respectively:

$$
E_{p}=0.5 \rho g \eta^{2}
$$

$$
\begin{aligned}
E_{k} & =0.5 \rho\left\{u_{\alpha}^{2}(\eta+h)\right. \\
& +u_{\alpha}\left\{u_{\alpha x x}\left[-1 / 3\left(\eta^{3}+h^{3}\right)+z_{\alpha}^{2}(\eta+h)\right]\right. \\
& \left.+\left(h u_{\alpha}\right)_{x x}\left[-\left(\eta^{2}-h^{2}\right)+2 z_{\alpha}(\eta+h)\right]\right\} \\
& +u_{\alpha x x}^{2}\left[1 / 20\left(\eta^{5}+h^{5}\right)-1 / 6 z_{\alpha}^{2}\left(\eta^{3}+h^{3}\right)+1 / 4 z_{\alpha}^{4}(\eta+h)\right] \\
& +u_{\alpha x x}\left(h u_{\alpha}\right)_{x x}\left[1 / 4\left(\eta^{4}-h^{4}\right)-1 / 3 z_{\alpha}\left(\eta^{3}+h^{3}\right)\right. \\
& \left.-1 / 2 z_{\alpha}^{2}\left(\eta^{2}-h^{2}\right)+z_{\alpha}^{3}(\eta+h)\right] \\
& +\left(h u_{\alpha}\right)_{x x}^{2}\left[1 / 3\left(\eta^{3}+h^{3}\right)-z_{\alpha}\left(\eta^{2}-h^{2}\right)+z_{\alpha}^{2}(\eta+h)\right] \\
& \left.+1 / 3 u_{\alpha x}^{2}\left(\eta^{3}+h^{3}\right)+u_{\alpha x}\left(h u_{\alpha}\right)_{x}\left(\eta^{2}-h^{2}\right)+\left(h u_{\alpha}\right)_{x}^{2}(\eta+h)\right\}
\end{aligned}
$$

where $g$ represents the gravitational acceleration $\left[\mathrm{m} / \mathrm{s}^{2}\right], u_{\alpha}$ the horizontal velocity evaluated at water depth $z_{\alpha}[\mathrm{m} / \mathrm{s}], \eta$ the water free surface elevation $[\mathrm{m}]$ and $\rho$ the water density $\left[\mathrm{kg} / \mathrm{m}^{3}\right]$. The subscript ' $\mathrm{x}$ ' denotes spatial partial derivatives.

The rate of wave transmission, wave reflection and wave energy dissipation is plotted versus the relative structure width for different relative incident wave conditions and relative submergence depths in Figs. 11, 12 and 13, respectively. The results of the numerical tests without the structure on the horizontal shelf, for which $K_{t}=1.0, K_{r}=0.0$ and $K_{d}=0.0$, represented reference tests for those with the barrier. The damping performance of the structure was found to be dependent on the wave breaking conditions induced over the barrier crest. 
A very weak reduction of the wave energy, achieved by partial reflection of the incident wave, was attributed to nonbreaking waves $\left(\mathrm{K}_{\mathrm{d}}=0.0\right)$. It was found that the rate of wave transmission was affected by the relative structure width up to the value of ca. $\mathrm{B} / \mathrm{L}_{\mathrm{i}}=0.2$ and beyond this threshold it tended to be constant: ca. 0.98 for $\mathrm{d}_{\mathrm{r}} / \mathrm{h}=0.5$, ca. 0.96 for $\mathrm{d}_{\mathrm{r}} / \mathrm{h}=0.4$ and ca. 0.92 for $\mathrm{d}_{\mathrm{r}} / \mathrm{h}=0.3$. Same trend was also observed for the reflection coefficient, which ranged from ca. 0.23 for $\mathrm{d}_{\mathrm{r}} / \mathrm{h}=0.5$, to ca. 0.29 for $\mathrm{d}_{\mathrm{r}} / \mathrm{h}=0.4$ and ca. 0.41 for $\mathrm{d}_{\mathrm{r}} / \mathrm{h}=0.3$.

Additional wave energy reduction was achieved for waves breaking over the barrier crest, thus increasing significantly the damping performance of the structure. Unlike the nonbreaking wave conditions, the transmission coefficient decreased with the increasing relative submergence depth and reached its minimum of 0.75 for $\mathrm{H}_{\mathrm{i}} / \mathrm{h}=0.25, \mathrm{~d}_{\mathrm{r}} / \mathrm{h}=0.3$ and $\mathrm{B} / \mathrm{L}_{\mathrm{i}}=1.0$. The wave reflection coefficient tended to be constant for values of the relative structure width larger than 0.2 and yielded ca. 0.21 for $\mathrm{d}_{\mathrm{r}} / \mathrm{h}=0.5$, ca. 0.26 for $\mathrm{d}_{\mathrm{r}} / \mathrm{h}=0.4$ and ca. 0.33 for $\mathrm{d}_{\mathrm{r}} / \mathrm{h}=0.3$. The rate of wave energy dissipation increased significantly with widening of the structure and was additionally influenced by the relative incident wave height and the relative submergence depth. The maximum wave energy dissipation coefficient $K_{d}=0.59$ was achieved for the widest barrier of $B / L_{i}=1.0$, smallest freeboard of $d_{r} / h=0.3$ and highest relative incident wave height of $\mathrm{H}_{\mathrm{i}} / \mathrm{h}=0.25$.

As indicated by the numerical results, an optimal structure width of ca. $\mathrm{B} / \mathrm{L}_{\mathrm{i}}=0.2$ exists only for nonbreaking waves. However the corresponding attenuation performance of the structure is not satisfactory, less than $10 \%$. In case of breaking waves, wave reduction by almost $25 \%$ was achieved and it would be expected to be higher when considering relative structure widths larger than 1.0.

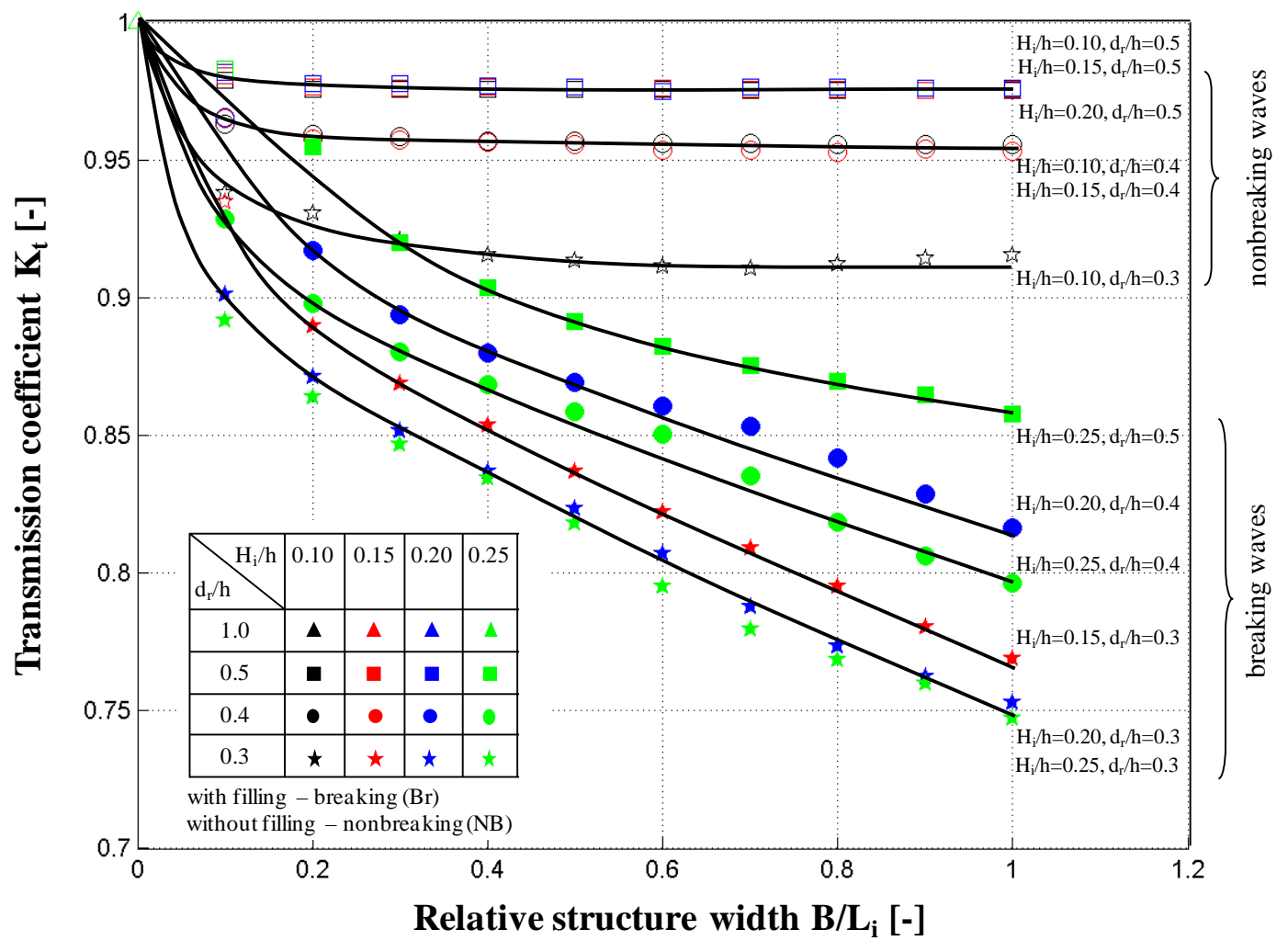

Figure 11. Computed wave transmission coefficient. 


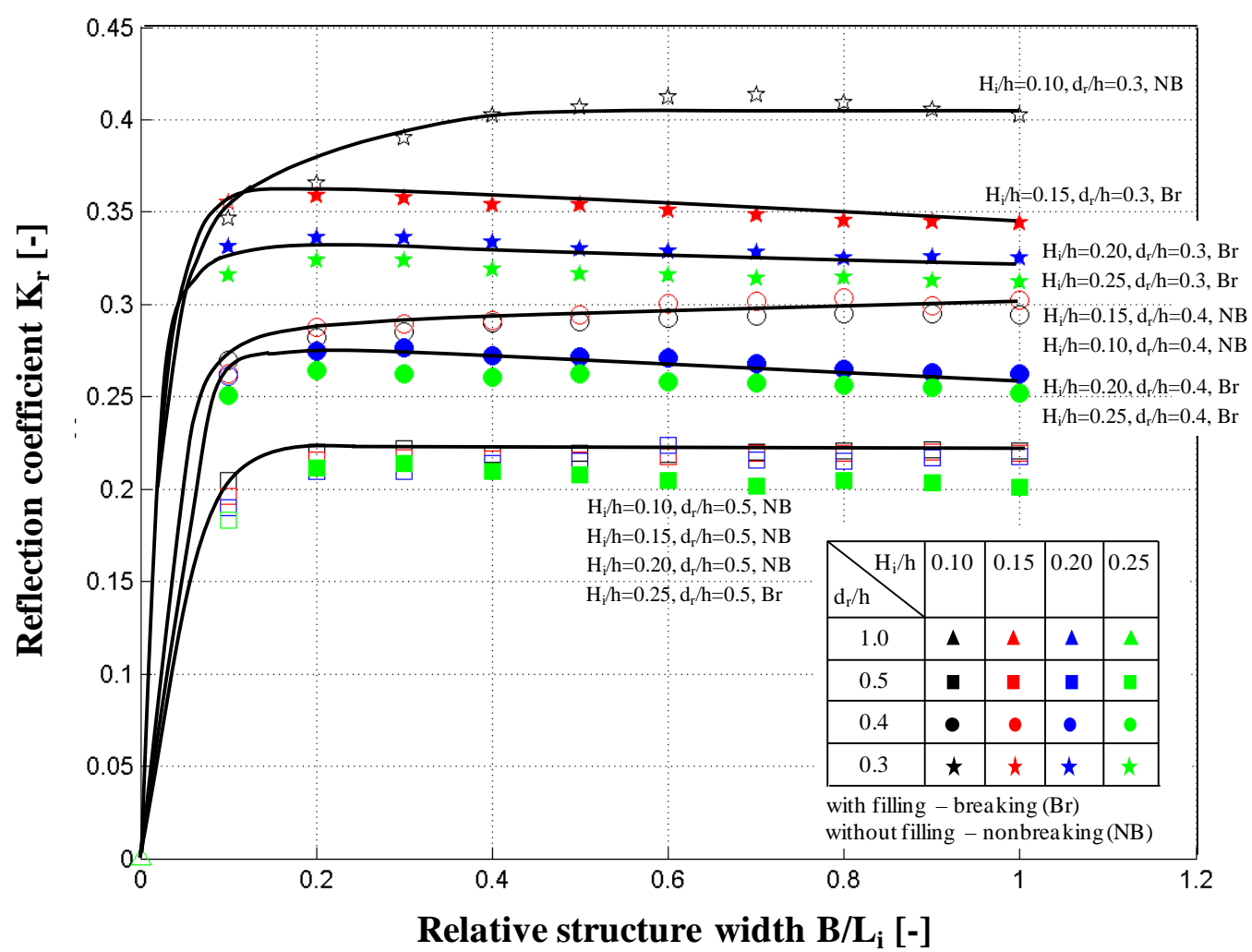

Figure 12. Computed wave reflection coefficient.

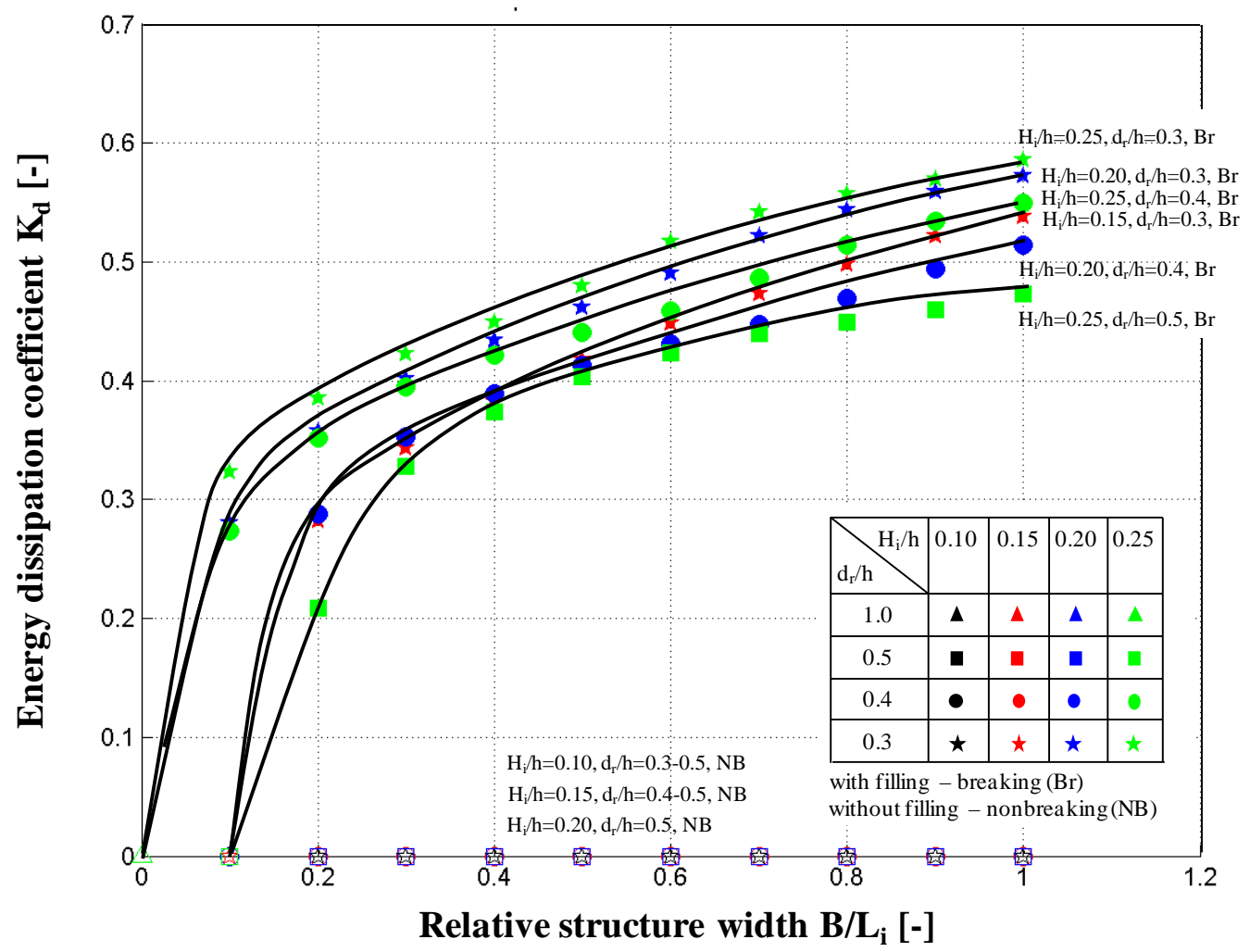

Figure 13. Computed wave energy dissipation coefficient. 


\section{CONCLUDING REMARKS}

The laboratory experiments on the solitary wave interaction with impermeable submerged structures of finite widths contributed significantly to the better understanding of the involved nonlinear processes such as those associated with wave breaking and wave fission. The five identified evolution modes were primarily governed by relative incident wave height $H_{i} / d_{r}$ and relative structure width $B / L_{i}$ and were found to be independent of the structure shape. Particularly challenging was the determination of the number of the solitons emerged from the incident solitary wave due to the water depth change over the submerged structure (considered in this study however for nonbreaking waves only). Up to relative submergence depth of $\mathrm{d}_{\mathrm{r}} / \mathrm{h}=0.33$, the investigated submerged structures likely behave in a very similar manner as their infinitely long counterparts examined in the previous studies (solitons number ranged from 2 to 4 ). This was not the case for very small relative submergence depths of $d_{r} / h=0.17$, for which twice as many solitons were generated over the submerged steps in comparison to the structures of a finite width.

The effectiveness of the submerged impermeable structure in wave attenuation was determined under more realistic tsunami conditions $\left(\mu=\mathrm{h} / \mathrm{L}_{\mathrm{i}}=0.01\right)$ compared to the laboratory experiments. The approach of calculating the transmission, reflection and wave energy dissipation coefficients in terms of wave energy was most appropriate in the case of the generation of the wave fission. As expected, breaking wave conditions above the structure crest govern the damping performance of the barrier. Negligible tsunami attenuation (less than 10\%) was attributed to the nonbreaking waves. Widening of the structure more than $\mathrm{B} / \mathrm{L}_{\mathrm{i}}=0.2$ did not improve the ratio of wave attenuation. The inception of wave breaking was controlled by both relative incident wave height $H_{i} / h$ and relative submergence depth $d_{r} / h$, however the ratio of wave energy dissipation was dependent on relative structure width $B / L_{i}$ (i.e. longer structure crest caused more intensive energy dissipation due to the longer wave propagation in the shallower water). The maximum tsunami attenuation, however only $25 \%$, was achieved for a structure width comparable to the incident wavelength. This clearly indicates that construction of such large structures would not be practical considering the high costs and relatively poor damping performance. However, making the submerged structure porous will certainly contribute to dissipate more energy and thus to tsunami damping. Moreover, it is recommended to examine the attenuation of the generated short-period solitons by the further defence lines suggested by Oumeraci (2006).

\section{ACKNOWLEDGMENTS}

This study was performed in the framework of a Ph.D. scholarship granted by the DFG (Deutsche Forschungsgemeinschaft) within the Graduate College "Fluid-Structure Interaction" with additional financial support of the Leichtweiß-Institute for Hydraulic Engineering and Water Resources, both at the Technische Universität Braunschweig. The authors would like to express their gratitude to Patrick Lynett, Ph.D. for his overall support, in particular for the introduction to the numerical modelling using the COULWAVE model, and also to Stefan Koß, M.Sc., for the assistance in conducting the experiments.

\section{REFERENCES}

Aono, T., and E.C. Cruz. 1996. Fundamental characteristics of wave transformation around artificial reefs, Coastal Engineering, 25, 2298-2311.

Bleck, M. 2006. Wave attenuation by artificial reefs, PIANC Magazine, 125, 5-20.

Dean, R.G., and R.G. Dalrymple. 1991. Water Wave Mechanics for Engineers and Scientists, Advanced Series on Ocean Engineering, Vol. 2, World Scientific, 353 pp.

Germain, J.P. 1984. Coeficients de réflexion et de transmission en eau peu profonde, Rozprawy Hydrotechniczne, 46, Instytut Budownictwa Wodnego, Gdańsk, Poland (in French), 5-13.

Goring, D.G. 1992. Propagation of long waves onto shelf, Journal of Waterway, Port, Coastal and Ocean Engineering, 118(1), 43-61.

Grilli, S.T., M.A., Losada, and F. Martin. 1994. Characteristics of solitary wave breaking induced by breakwaters, Journal of Waterway, Port, Coastal, and Ocean Engineering, 120(1), 74-92.

Hara, M., T., Yasuda, and Y. Sakakibara. 1992. Characteristics of a solitary wave breaking caused by a submerged obstacle, Proceedings of $23^{\text {rd }}$ International Conference on Coastal Engineering, Venice, Italy, 253-266.

Johnson, R.S. 1972. Some numerical solutions of a variable-coefficient Korteweg-de-Vries equation (with application to solitary wave developed on a shelf), Journal of Fluid Mechanics, 54(1), 81-91. 
Kabbaj, A. 1985. Contribution à l’étude du passaga des ondes de gravité et de la génération des ondes internes sur un talus, dans le cadre de la théorie de l'eau peu profonde, Thése, Université Scientifique et Médicale de Grenoble (in French).

Lin, P. 2004. A numerical study of solitary wave interaction with rectangular obstacles, Coastal Engineering, 51, 35-51.

Liu, P.L.-F. 1994. Model equations for wave propagation from deep to shallow water, Advances in Coastal and Ocean Engineering, 1, World Scientific, 125-157.

Liu, P.L.-F., and Y. Cheng. 2001. A numerical study of the evolution of a solitary wave over a shelf, Physics of Fluids, 13(6), 1660-1667.

Losada, M., C. Vidal, and R. Median. 1989. Experimental study on the evolution of a solitary wave at an abrupt junction, Journal of Geophysical Research, 94(C10), 14557-14566.

Lynett, P. 2002. A multi-layer approach to modelling, generation, propagation, and interaction of water waves, PhD. Thesis, Cornell University, USA, pp.

Lynett, P. 2007. Effect of a shallow water obstruction on long wave runup and overland flow velocity, Journal of Waterway, Port, Coastal and Ocean Engineering, 133(6), 455-462.

Madsen, O.S., and C.C. Mei. 1969. The transformation of a solitary wave over and uneven bottom, Journal of Fluid Mechanics, 39(4), 781-791.

Nwogu, O. 1993. Alternative form of Boussinesq equations for nearshore wave propagation, Journal of Waterway, Port, Coastal, and Ocean Engineering, 119, 618-638.

Oumeraci, H. 2006. Near-and onshore tsunami effects - knowledge base generation and model development, Background Paper for DFG-Round Table Discussion "Near- and Onshore Tsunami Effects”, FZK, Hannover, Germany, http://www.fzk.uni-hannover.de/323.html.

Pilarczyk, K.W. 2003. Design of low-crested (submerged) structures - an overview, Proceedings of $6^{\text {th }}$ International Conference on Coastal and Port Engineering in Developing Countries, Colombo, Sri Lanka, 1-18.

Seabra-Santos, F.J., D.P., Renouvard, and A.M. Temperville. 1987. Numerical and experimental study of the transformation of a solitary wave over a shelf or isolated obstacle, Journal of Fluid Mechanics, 176, 117-134.

Strusińska, A. 2011. Hydraulic performance of an impermeable submerged structure for tsunami damping, Ibidem Publisher, Stuttgart, 199 pp.

Tappert, F.D., and N.J. Zabusky. 1971. Gradient-induced fission of solitons, Physical Review Letters, 27(26), 1774-1776. 